\title{
Range Extension Opportunities While Heating a Battery Electric Vehicle
}

John J. Meyer Hanon Systems

Jason Lustbader National Renewable Energy Laboratory

Nicos Agathocleous Hanon Systems

Antonio Vespa Hyundai-Kia America Technical Center Inc

John Rugh and Gene Titov National Renewable Energy Laboratory

Citation: Meyer, J.J., Lustbader, J., Agathocleous, N., Vespa, A. et al., "Range Extension Opportunities While Heating a Battery Electric Vehicle," SAE Technical Paper 2018-01-0066, 2018, doi:10.4271/2018-01-0066.

\section{Abstract}

he Kia Soul battery electric vehicle (BEV) is available with either a positive temperature coefficient (PTC) heater or an R134a heat pump (HP) with PTC heater combination [1]. The HP uses both ambient air and waste heat from the motor, inverter, and on-board-charger $(\mathrm{OBC})$ for its heat source. Hanon Systems, Hyundai America Technical Center, Inc. (HATCI) and the National Renewable Energy Laboratory jointly, with financial support from the U.S. Department of Energy, developed and proved-out technologies that extend the driving range of a Kia Soul BEV while maintaining thermal comfort in cold climates. Improved system configuration concepts that use thermal storage and waste heat more effectively were developed and evaluated. Range extensions of 5\%-22\% at ambient temperatures ranging from $5{ }^{\circ} \mathrm{C}$ to $-18^{\circ} \mathrm{C}$ were demonstrated. This paper reviews the three-year effort, including test data of the baseline and modified vehicles, resulting range extension, and recommendations for future actions.

\section{Introduction}

attery electric vehicle (BEV) range can be reduced by $50 \%$ or more in cold weather, as illustrated in Figure 1

[2] Error! Reference source not found. Two ambient temperatures are included, $-10^{\circ} \mathrm{C}$, on the left, and $0{ }^{\circ} \mathrm{C}$, on the right. The blue bars show the range of $100 \%$ when no heating is used; the red bars show a $\sim 50 \%$ reduction in range when a positive temperature coefficient (PTC) (electric resistance) heater is used, and a $\sim 30 \%$ improvement from the PTC range when a heat pump (HP) is utilized. However, a significant gap between no-heating and heating with a HP remains. A goal of this project is to reduce that gap further, enabling the sale of grid-connected electric-drive vehicles (GCEDVs) in climates that are considered too cold today.

Several technologies were evaluated, but it was found that thermal storage (TS) offered the best combination of cost, performance, and readiness. To minimize the negative effect on cost and mass, existing components in thermal contact with the cooling loop, including the power electronics and electric machine, were used for TS (did not include traction battery) [3]. In addition to TS, grill shutters with enhanced front-end sealing and improved waste heat management completed the "TS package."

Using a steady 50 -kph, 40-minute drive, the TS package was tested at $5^{\circ} \mathrm{C},-5^{\circ} \mathrm{C}$, and $-18{ }^{\circ} \mathrm{C}$. When the package was applied to the HP vehicle traction battery, energy reductions of 900 to $4,300 \mathrm{~kJ}$ were realized over the temperature range. When the same TS package was applied to a PTC-only vehicle, the energy savings increased to 1,800 to $5,000 \mathrm{~kJ}$. The bigger energy savings for the PTC-only vehicle results from two main areas: 1) the baseline power consumption is significantly higher than for the HP vehicle, leaving more room for improvement; and 2) the baseline PTC-only vehicle has no means for waste heat recovery, but it is included in the TS package.

Through this effort, significant traction battery savings have been demonstrated while heating a BEV, thus extending the cold-weather driving range and extending the viability of BEVs into colder climates. The hardware used to demonstrate the savings is application-ready.

\section{Baseline Architectures}

The Soul comes with two heating options. The base system is PTC-only, meaning any time heat is needed, electric current is passed through a heater to convert electrical energy directly into heat. Although functional, this method has poor efficiency and results in a significant range loss, as shown in Figure 1. A schematic of the refrigerant system for the base 
FIGURE 1 Effect of heating a BEV on driving range

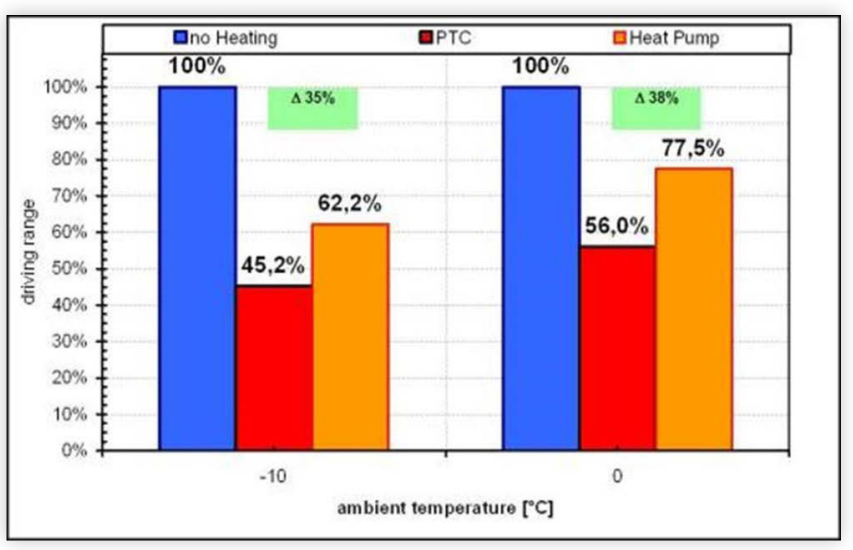

FIGURE 2 Schematic of production refrigerant system for PTC-only heating

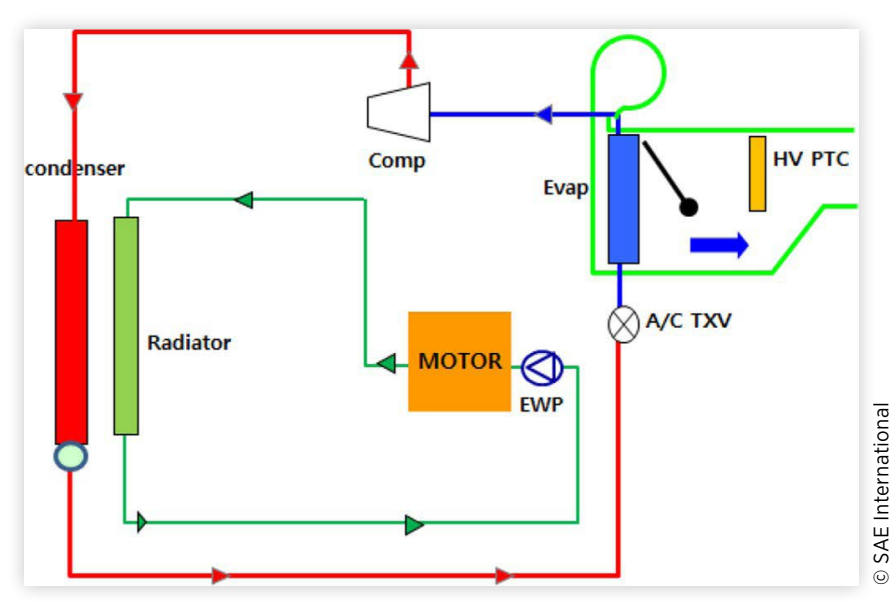

PTC-only vehicle is shown in Figure 2. As can be seen, the only modification from a typical internal combustion (IC) vehicle heating, ventilation, and air conditioning (HVAC) system is the use of a high-voltage PTC heater in place of a heater core.

The Soul also offers an HP option, which includes the PTC heater for conditions where it is either too cold for the HP to operate or when the heating demand is beyond what the HP can deliver. A schematic of that system is shown in Figure 3. Several differences from the refrigerant system of an IC engine vehicle are evident. The most obvious modification is the inclusion of an "inside condenser." The inside condenser performs a similar function as the heater core, but has hot discharge refrigerant gas from the compressor routed through it rather than hot glycol. Also evident is the chiller, which is used to transfer electric motor waste heat to the refrigerant and then to the cabin. Other differences include the "dehumidification line," which routes cold refrigerant to the evaporator during HP operation; the outside condenser bypass; multiple lines and valves required for the increased functionality; and an accumulator because the HP mode uses an orifice tube rather than a thermostatic expansion valve (TXV).

In addition to the HVAC systems above, the Soul BEV is equipped with heated and ventilated seats, heated steering
FIGURE 3 Schematic of production refrigerant system with HP

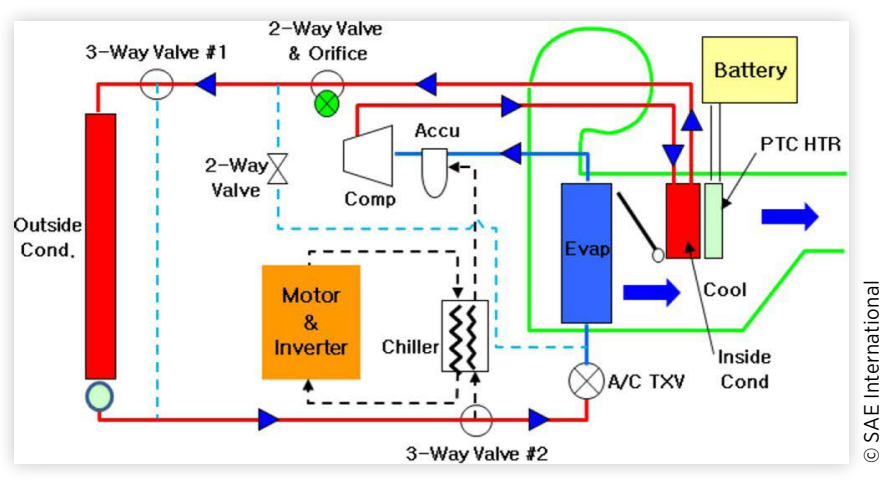

wheel, driver-only modes, and timed cabin preconditioning when plugged into the grid.

\section{Heating System Design Modeling and Evaluation}

NREL's CoolSim software, a thermal system modeling framework in Simulink [1], was used to evaluate emerging cabin heating solutions for electric vehicles. Multiple system variants, which included components/sub-systems such as HP, TS, and combinations of heat exchangers were studied to support the project design process. Control strategies for efficient operation were evaluated for selected systems.

All modeled systems were evaluated at three ambient conditions with temperatures of $+5^{\circ} \mathrm{C},-5^{\circ} \mathrm{C}$ and $-18^{\circ} \mathrm{C}$. The systems were controlled to deliver a specified heating capacity for each of the conditions. When TS was used, a transient process that accounted for depletion of stored energy was modeled. A quasi-transient solution algorithm was used for modeling both glycol and refrigerant loops []‥ This method was found to be a good balance between simulation speed and accuracy.

Two major system variants emerged in the design process. The first variant is referred to as Heat Pump with Thermal Storage (HPTS). This system included a HP that was capable of accepting heat from both ambient air through a front-end heat exchanger (FEHX) acting as an evaporator, and from TS by a coolant-to-refrigerant chiller. In addition, the system included a glycol-based preconditioner that delivered energy, both waste heat and stored thermal energy, from storage directly to the cabin. The system also included a PTC heater to supplement other heat sources when needed. The schematic of this system is depicted in Figure 5.

The second system variant, referred to as PTC-Only with Thermal Storage (POTS), avoided the complexity of using an $\mathrm{HP}$ and relied on a glycol loop delivering heat to the cabin from the TS loop through a preconditioner. A PTC heater was used when the preconditioner capacity alone was not sufficient. This system variant provided the benefits of using the motor and the invertor as TS and waste heat source while producing a simpler and lower cost design. The schematic of this variant is shown in Figure 8 . 
FIGURE 4 Electrical energy required by thermal system varients using pre-heat over the project's 40-min drive cycle at selected ambient temperatures

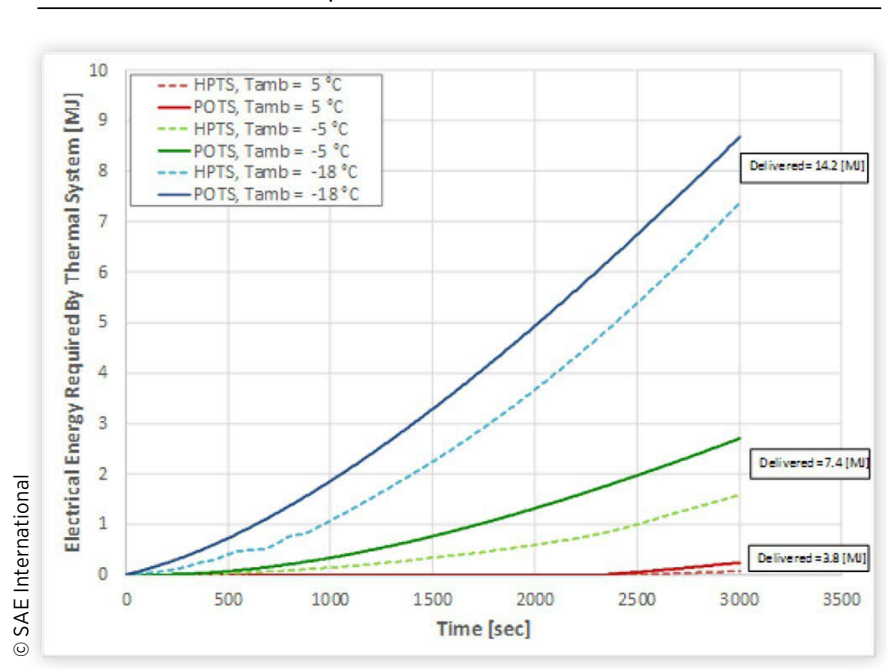

Figure 4 shows a system performance comparison made based on electrical energy spent while delivering the same thermal capacity for each of the ambient conditions. Averaging due to small variations caused by controls, the delivered thermal energy for the two systems was $1,264 \mathrm{~W}, 2,458 \mathrm{~W}$, and 4,722 W at ambient temperatures of $5^{\circ} \mathrm{C},-5^{\circ} \mathrm{C}$, and $-18^{\circ} \mathrm{C}$, respectively. The average delivered thermal energy over the cycle is provided in the graph. The delivered energy is a combination of stored thermal energy, waste heat from the power electronics and electric machine, and PTC heater and/or compressor (for HPTS). As the TS is depleted, the system requires more electric energy to deliver the same thermal energy, which causes the increasing slope of the electrical energy demand curves.

\section{System Modifications and Initial Evaluations}

\section{HP System Modifications}

To facilitate the new modes of operation, namely storing and harvesting heat, the glycol system was modified as shown in Figure 5. Most notably, a preconditioner (preCon) was added to the HVAC case, and a heater was added to the glycol loop. The total incremental mass is less than $4 \mathrm{~kg}$, including the coolant, hoses, and additional front-end sealing. With these additions, glycol can first transfer energy from the heater to the thermal mass, heating it to $\sim 55^{\circ} \mathrm{C}$. Once the drive starts, thermal energy can be transferred directly from the TS to the cabin. The preCon is located in the HVAC case before the inside condenser and the PTC air heater. Due to its location, it can be used to precondition (thus the name) the incoming air to reduce the amount of heating required. It is this feature that allows operation even when the TS temperature becomes near the ambient temperature.

In addition to the glycol loop modifications, to reduce heat loss from storage, the front-end sealing of the vehicle was
FIGURE 5 Schematic of glycol loop built into Kia Soul with HP

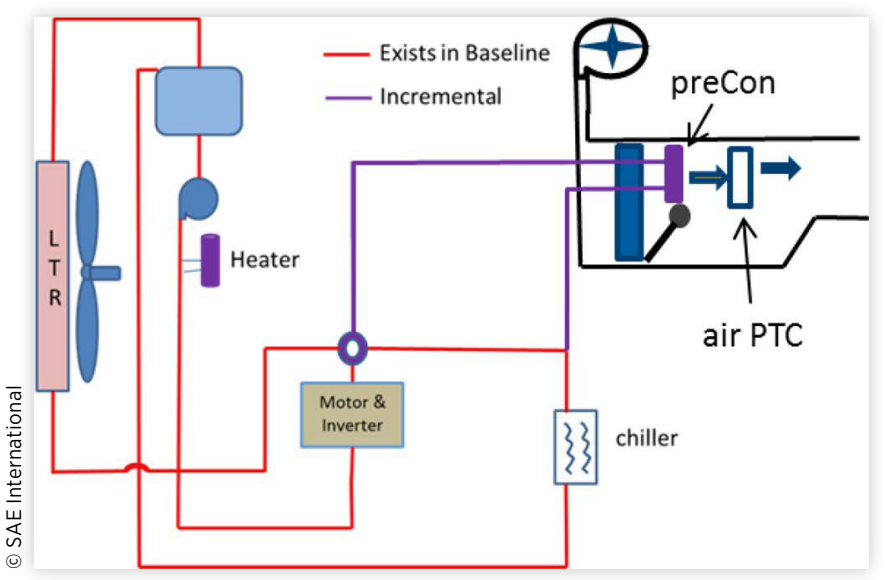

enhanced. Through the implementation of grill shutters and additional seals, the rate of heat loss from the warm motor was reduced by approximately $50 \%$.

\section{Initial Evaluations}

The new hardware was evaluated on the vehicle rather than a test bench. Having an electric vehicle in a temperaturecontrolled chamber offers many benefits compared to bench testing. Along with evaluations in the soak room, the vehicle was tested on the road and in a climatic wind tunnel.

Figure 6 shows the system response to passing warm glycol through the preCon. The soak room was set to a temperature of $-5{ }^{\circ} \mathrm{C}$ and the vehicle's cabin controls were set to "72 Auto." The controls were allowed to operate with the production control strategy. After about 14 minutes, the power consumption stabilized at $\sim 800 \mathrm{~W}$ of PTC power and $\sim 550 \mathrm{~W}$ of compressor power. The power consumption values were obtained from vehicle controller area network output, with a measurement uncertainty of $\pm 2 \%$. The glycol pump was then turned on, allowing heat to be transferred from TS to incoming

\section{FIGURE 6 Initial evaluation of preCon concept}

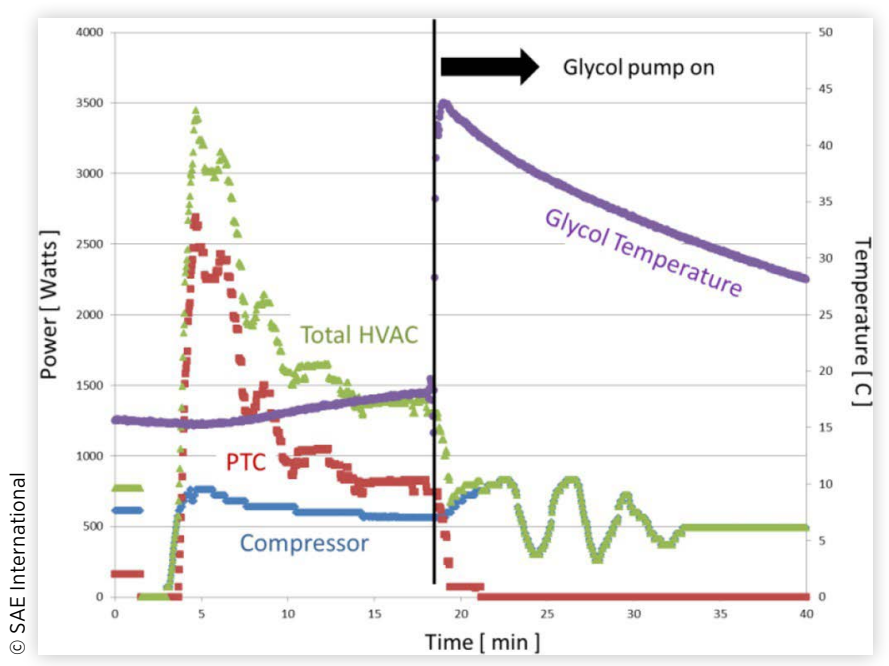




\section{FIGURE 7 Road evaluation of preCon concept at $6{ }^{\circ} \mathrm{C}$}

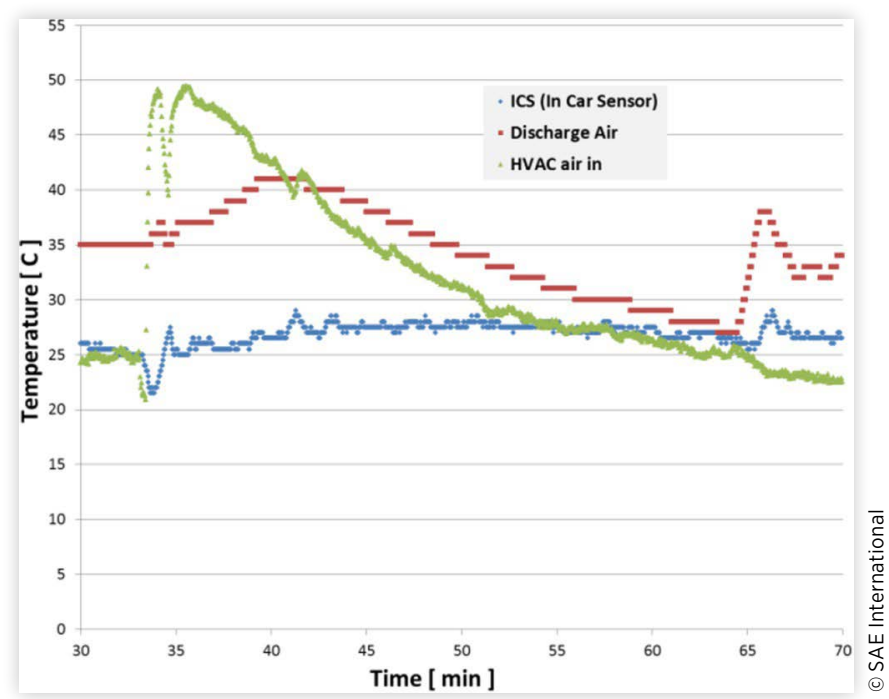

air prior to it passing over the inside condenser. The warm glycol then flowed through the chiller, enhancing the HP performance. The result was a significant reduction in the amount of battery power required to bring the airstream to the desired outlet temperature. In Figure 6, the compressor power is the blue line, the PTC power is the red line, and the sum of the two, total HVAC power, is the green line. Before the pump was engaged, the total HVAC power was about $1,350 \mathrm{~W}$. Shortly after the glycol started flowing, the PTC heater turned off and, after a few oscillations, the compressor drew about $500 \mathrm{~W}$. This represents a $63 \%$ reduction in HVAC power requirements, and was maintained for over 20 minutes.

The preCon concept was also evaluated on the road. For these tests the production PTC was used to precondition the cabin, and the glycol heater was used to build TS in the test car. At an ambient temperature of $6^{\circ} \mathrm{C}$ with the interior preconditioned and the electric drivetrain warmed to $60^{\circ} \mathrm{C}$, the heat transferred from TS to the cabin via the preCon was more than sufficient to keep the cabin comfortable for over 30 minutes. Figure 7 shows that near the end of preconditioning, at the 30-minute mark, both the in-car-sensor (ICS - green data) and the discharge air temperature (red data) had stabilized. At about 33.5 minutes, the test started, and warm glycol flowed through the preCon. Note the increase in HVAC-air-in temperature when the test started, and the glycol pump was turned on. Neither the PTC nor the compressor (HP) came on as the preCon supplied all the necessary heat. The preCon, in fact, supplied too much heat to the cabin as is evidenced by both the in-car-sensor and the discharge air temperature increasing. As TS depletes, the discharge temperature slowly decreases, and eventually the HP compressor engaged at about 64 minutes into the test. Temperatures were monitored with type $\mathrm{T}$ thermocouples with a standard uncertainty of $\pm 0.5^{\circ} \mathrm{C}$.

\section{PTC-Only Modifications}

Very similar modifications were made to a PTC-only BEV, creating the POTS system. The modified glycol system, shown
FIGURE 8 Glycol loop architecture for PTC-only with TS, POTS

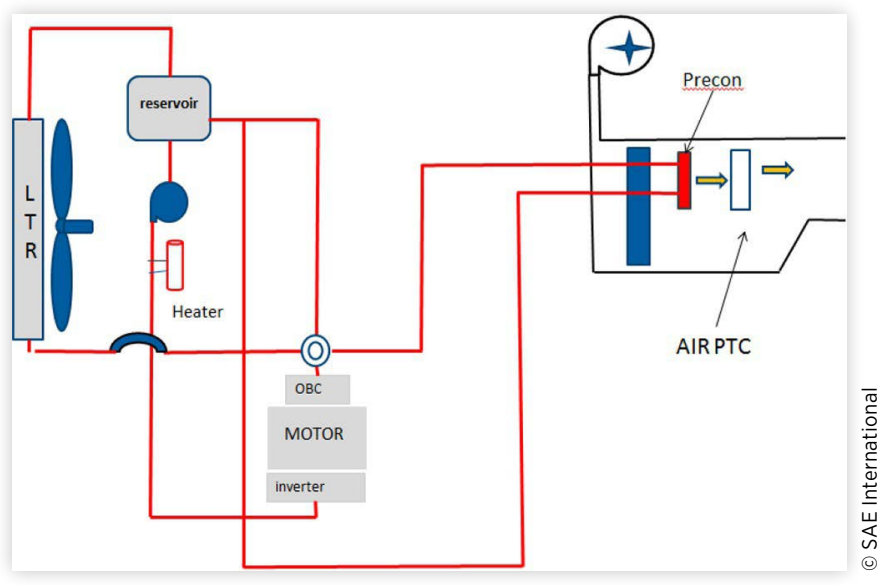

in Figure 8, includes hoses and a heat exchanger so that the waste heat can be delivered to the cabin via the preCon. The modifications require an inclusion of a four-way glycol valve immediately downstream of the power electronics. This valve allows for control of the glycol flow path so that required functionality can be met. The three outlet positions include: 1) to the preCon, 2) to the reservoir, and 3) to the low-temperature radiator (LTR).

\section{Vehicle Testing}

\section{Heat Pump Testing}

The preCon is very good at adding heat to the HVAC air flow. Figure 9 shows the $+5^{\circ} \mathrm{C}$ test air temperatures increase across the preCon (blue), and the air temperatures increase across the inside condenser and PTC (red). The majority of the energy for warming the cabin is from the stored and gleaned energy via the preCon. As Figure 9 shows, $100 \%$ of the heat to the cabin was supplied by TS for the first five minutes. Even after 40 minutes, a majority of the of the incoming air temperature increase, and thus energy, came from TS and/or waste heat recovery facilitated by the preCon. Delivery of significant heat to the cabin through the preCon after 40 minutes is a result of power electronics waste heat adding to the original stored thermal energy.

Analysis of the modified vehicle data shows that, during the 40 -minute drive, approximately $2,700 \mathrm{~kJ}$ of heat was delivered to the airstream via the preCon and $800 \mathrm{~kJ}$ came from the inside condenser. Further analysis shows that of the $2,700 \mathrm{~kJ}$, slightly more than half came from the stored heat and slightly less than half came from delivering waste heat to the cabin. For the first 20 minutes of the drive, approximately $70 \%$ more heat came from stored energy (than reclaimed waste heat). For the final 20 minutes of the drive, more waste heat was delivered to the cabin than from stored energy. This shows that for heating, stored energy is more important for shorter drives. For longer drives, however, the ability to deliver waste heat directly to the cabin becomes the dominant factor. 
FIGURE 9 Air temperature increase at $5^{\circ} \mathrm{C}$ from preCon (Top, Blue) and inside condenser (Bottom, Red)

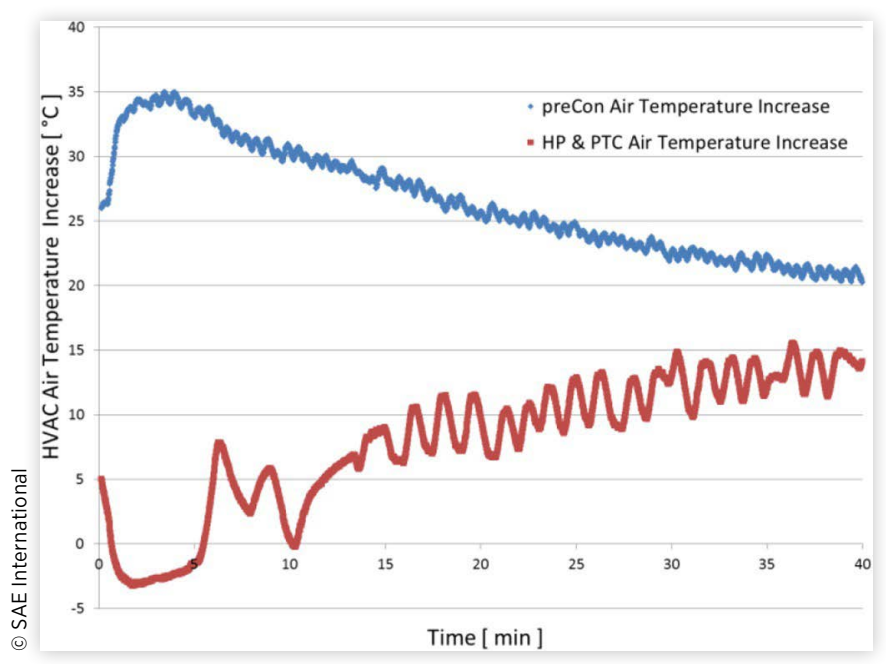

The oscillations of the red line in Figure 9 (heat pick-up over the inside condenser) are the result of the compressor cycling, because even at the minimum RPM, the HP system generates more heat than the cabin requires. The PTC never came on.

The traction battery energy consumed for heating during the $5^{\circ} \mathrm{C}, 40$-minute climate system test are shown in Figure 10. The blue (upper) line shows the baseline HP system consumed over $1,100 \mathrm{~kJ}$ for maintaining comfort. The red (lower) line shows the same vehicle modified to include TS with the HPTS system used less than $300 \mathrm{~kJ}$ during the test. This includes nearly zero power consumption for the first five minutes as both the PTC and HP remained off while the TS was warm enough to provide sufficient airflow at a high enough temperature to maintain interior temperatures.

This test shows approximately $68 \%$ reduction in HVAC energy consumption during the drive cycle. However, because the baseline energy consumption at this mild condition is low,

FIGURE 10 Energy consumption for heating at $5{ }^{\circ} \mathrm{C}$ for a steady $50 \mathrm{kph}$ drive

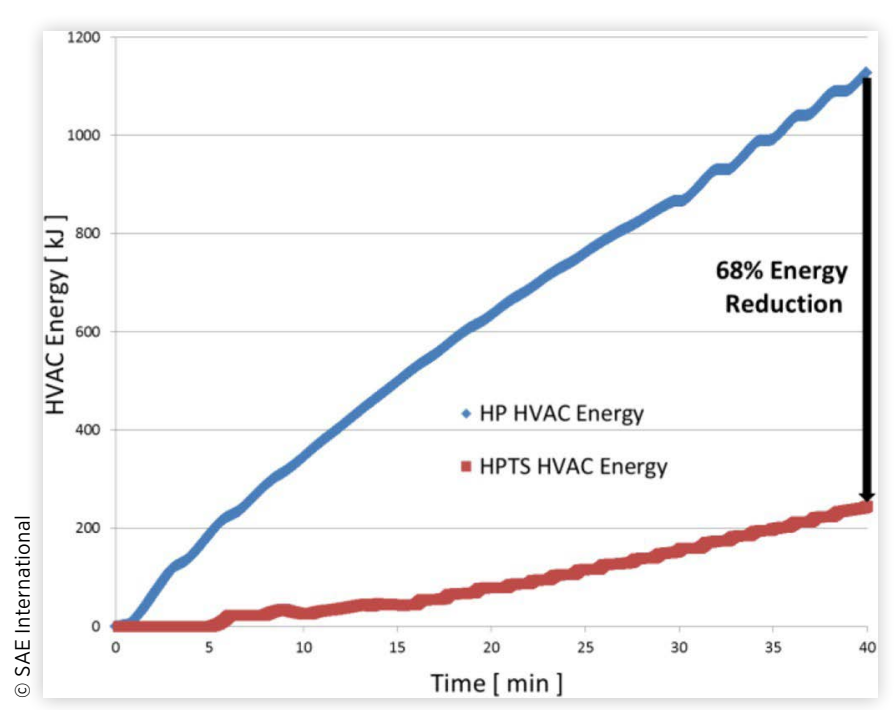

(c) 2018 SAE International. All Rights Reserved. the range extension resulting from the savings is also low. The $68 \%$ reduction in energy consumption for heating results in the batteries having sufficient charge to extend the range $1.5 \mathrm{~km}$.

Similar to the $5{ }^{\circ} \mathrm{C}$ results, at $-5{ }^{\circ} \mathrm{C}$ the preCon was the significant contributor of heat to the cabin for the first 20 minutes, after which the HP became the dominant energy source. The air temperature rise across the preCon at $-5{ }^{\circ} \mathrm{C}$ is larger than at $5^{\circ} \mathrm{C}\left(\sim 45^{\circ} \mathrm{C}\right.$ vs. $\left.\sim 35^{\circ} \mathrm{C}\right)$ due to the incoming air being cooler but TS starting out at the same temperature. For the first 20 minutes of the drive, the compressor cycled, as there was significant heat transfer from the preCon and thus very little additional heat was needed to maintain a comfortable interior temperature. After 20 minutes, however, the TS was depleted to the point that the compressor (HP) operation was continuous to supply the heat requested of the inside condenser. Similar to the $5^{\circ} \mathrm{C}$ case, during the first 22 minutes of the drive, a majority of the heat was delivered via the preCon from the TS and waste heat generation. For the final 18 minutes, the HP was the major heat contributor to the cabin.

Figure 11 compares the HVAC energy consumption for the $-5{ }^{\circ} \mathrm{C}$ tests. It shows that the HVAC energy consumed during the $-5{ }^{\circ} \mathrm{C}$ test was reduced from $3,000 \mathrm{~kJ}$ for the baseline Kia Soul HP system (blue, or upper line) to $1,230 \mathrm{~kJ}$ (red, or lower line) when TS, the preCon, and grill shutters were added to the system. Although the percentage reduction in energy consumed dropped to $59 \%$, the magnitude of the savings increased to $1,770 \mathrm{~kJ}$, allowing an extension of $2.9 \mathrm{~km}$.

Again, at $-18^{\circ} \mathrm{C}$ the preCon provided the majority of the heating energy for about 19 minutes, after which the HP and PTC supplied the majority of the heating energy.

At $-18{ }^{\circ} \mathrm{C}$ the traction battery energy consumption for heating the cabin was reduced by $48 \%$ when the enhancements were added to the production HP system. The $48 \%$ reduction equates to over $4,000 \mathrm{~kJ}$, as shown in Figure 12 . This energy reduction would result in a range extension of about $6 \mathrm{~km}$.

\section{FIGURE 11 Energy consumption for heating at $-5{ }^{\circ} \mathrm{C}$ for a} steady $50 \mathrm{kph}$ drive

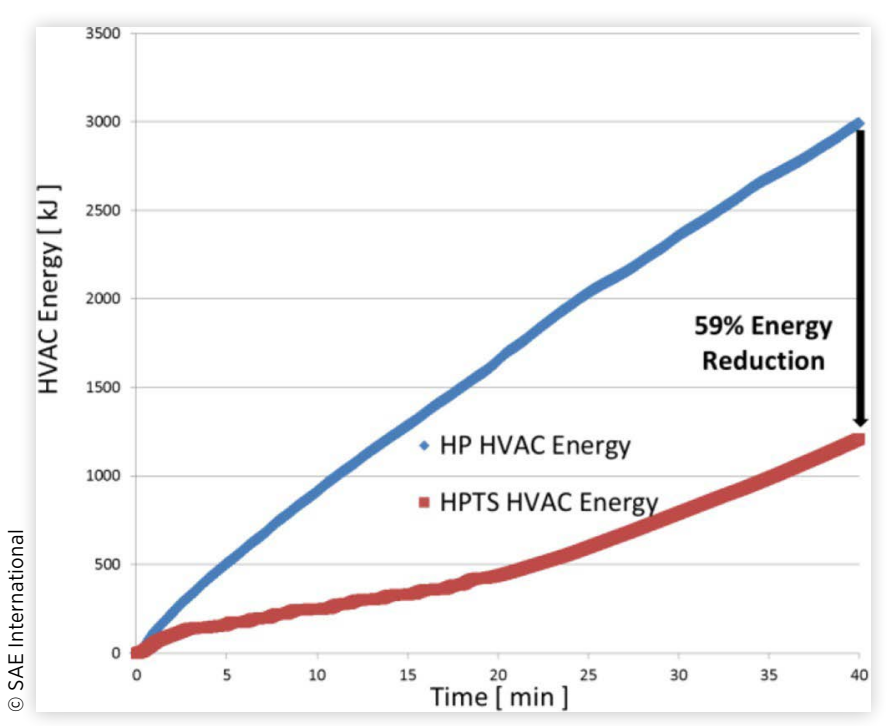




\section{FIGURE 12 Energy consumption for heating at $-18{ }^{\circ} \mathrm{C}$}

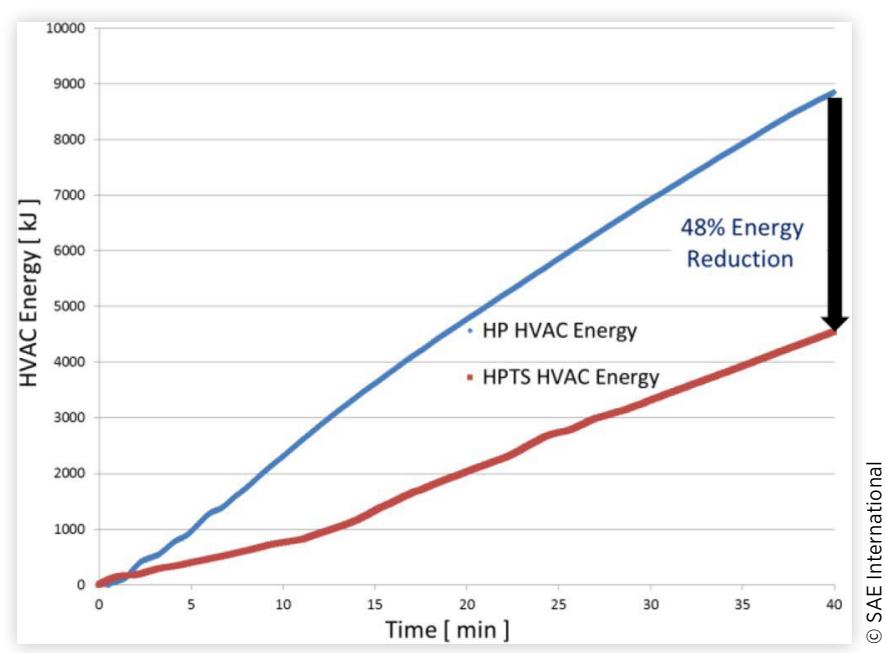

FIGURE 13 PTC-only HVAC energy consumption at $5{ }^{\circ} \mathrm{C}$

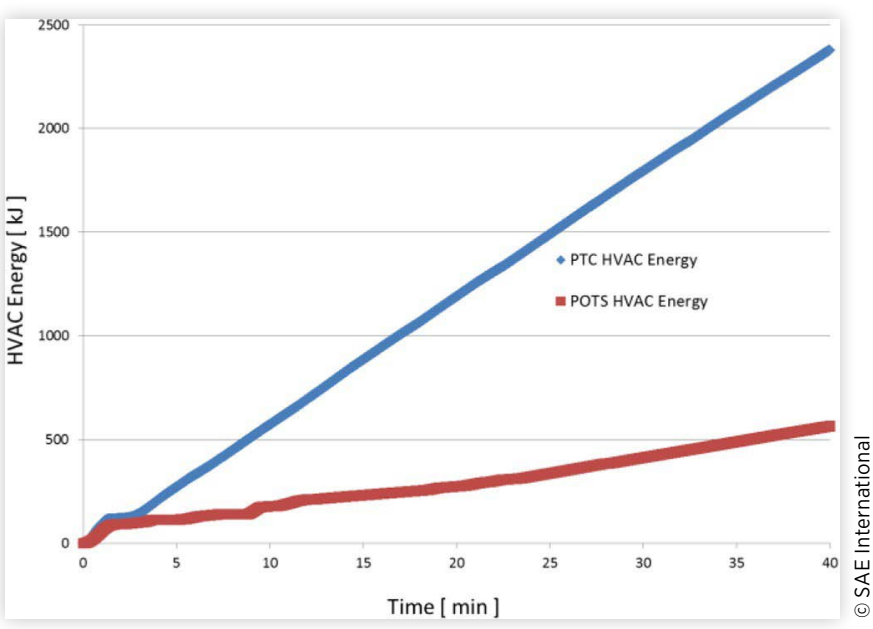

\section{PTC-Only Testing}

The PTC-only vehicle was also run at the three ambient conditions of $5{ }^{\circ} \mathrm{C},-5{ }^{\circ} \mathrm{C}$, and $-18{ }^{\circ} \mathrm{C}$ using the same test methodology as the previous HP testing. The cabin was preconditioned with the production strategy. The baseline performance was established and then the vehicle was modified to include the TS system, POTS. The installed hardware also has the ability to transport motor waste heat to the cabin very efficiently. To reduce heat loss to ambient, the vehicle was equipped with improved front-end sealing,

The results from the 40-minute, $50-\mathrm{kph}$ drive are shown in Figures 13, 14, and $\underline{15}$. Like the HP testing, the warmer the condition the greater the percentage reduction in energy consumption, but the magnitude of the savings decreases. Also of note, the baseline energy consumption is much higher for the PTC-only vehicle than for the HP system. At $-5{ }^{\circ} \mathrm{C}$, for example, the baseline HP system consumed $40 \%$ less energy than the baseline PTC-only system due to higher heating efficiency.

\section{FIGURE 14 PTC-only HVAC energy consumption at $-5^{\circ} \mathrm{C}$}

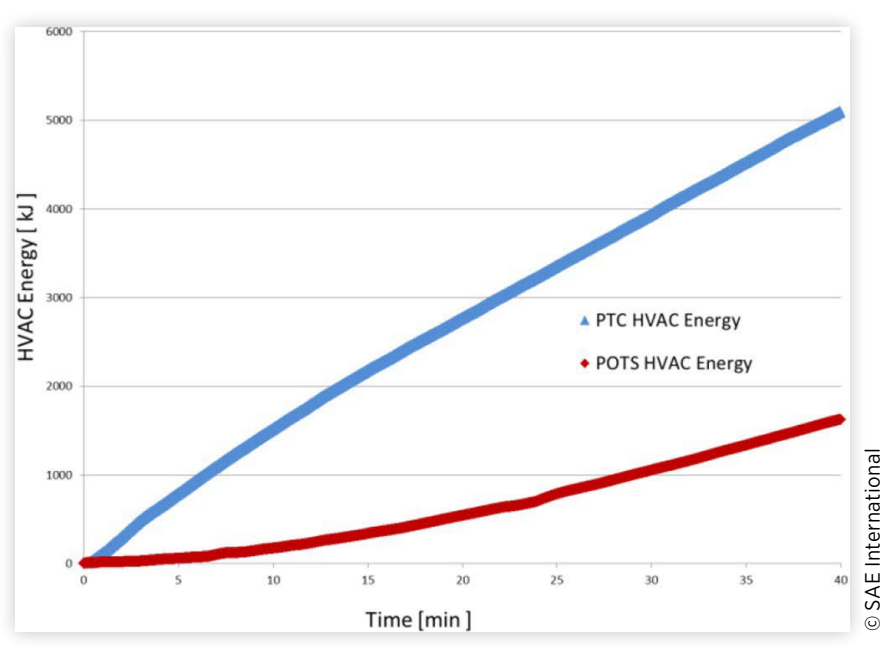

FIGURE 15 PTC-only HVAC energy consumption at $-18^{\circ} \mathrm{C}$

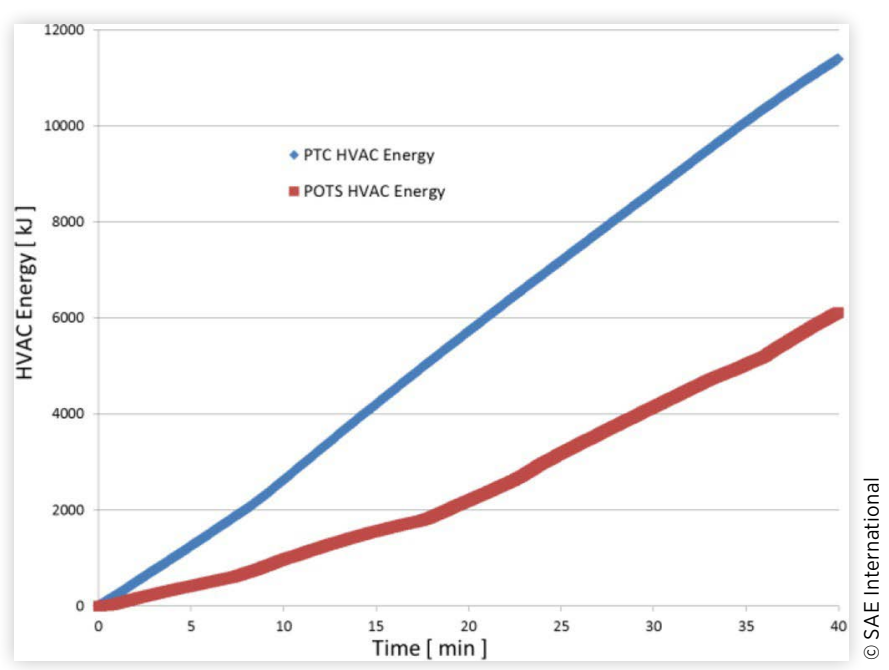

\section{Dehumidification Testing}

Figure shows the results of the PTC-only baseline dehumidification test. The controls were placed at " 72 Auto" and the car was run in a wind tunnel at $50 \mathrm{kph}$ with no solar load and no TS. Starting at $28{ }^{\circ} \mathrm{C}$ and $25 \%$ relative humidity, the ambient temperature was decreased by $2{ }^{\circ} \mathrm{C}$ every 10 minutes. The black line shows tunnel temperature, the green line shows compressor power, and the red line is PTC power. As can be seen, the PTC barely came on at $28^{\circ} \mathrm{C}$, as the cabin requires cooling at this condition. As the temperature dropped, the compressor power decreased, and the PTC power increased, until at $16^{\circ} \mathrm{C}$ the compressor was cycling rapidly, and the PTC was providing $600-700 \mathrm{~W}$.

The modified vehicle (POTS) was tested under the same conditions. This time, however, the vehicle heating was predominately supplied by gleaned powertrain waste heat delivered to the cabin via the preCon.

Figure 17 shows the energy savings as a percentage of the baseline energy consumption. This energy savings results in 
FIGURE 16 Baseline dehumidification test with PTC-only vehicle

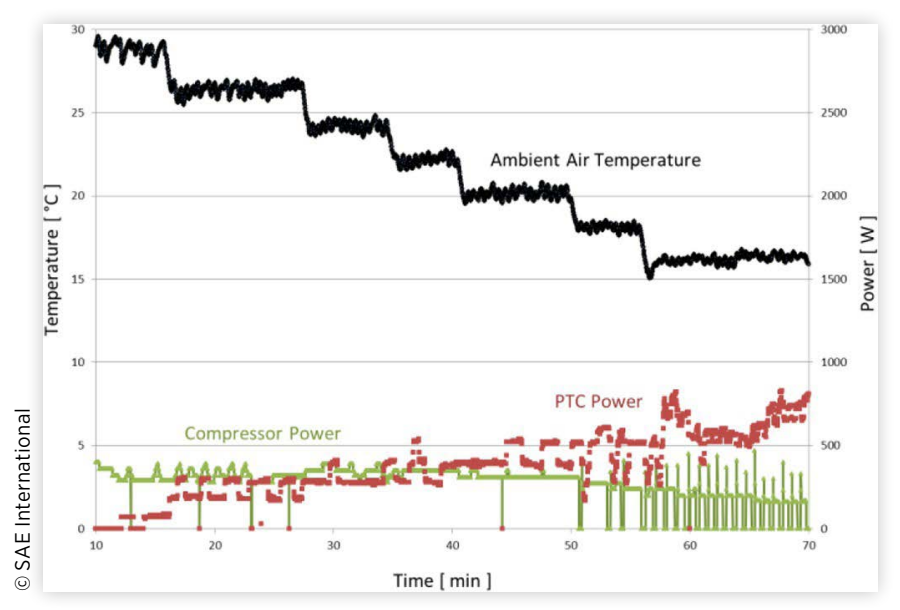

FIGURE 17 Power reduction of POTS HVAC system

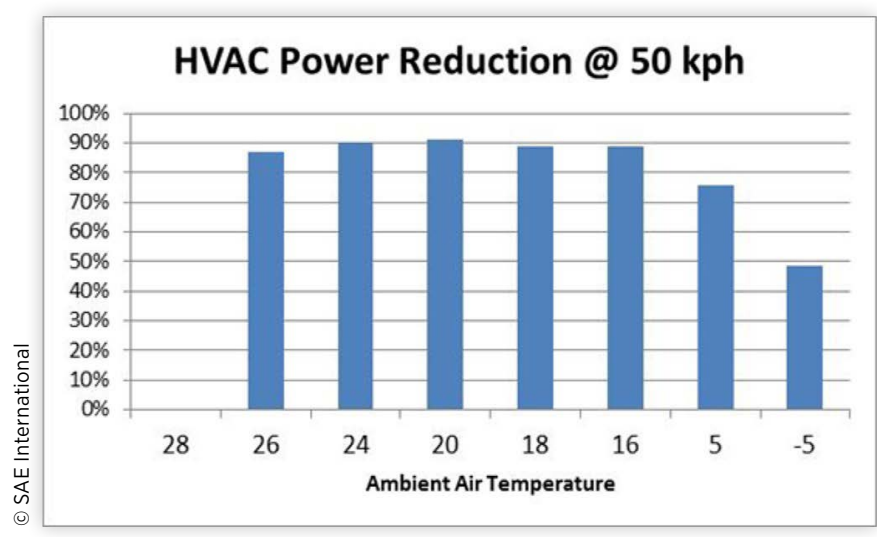

FIGURE 18 Range improvements due to POTS savings

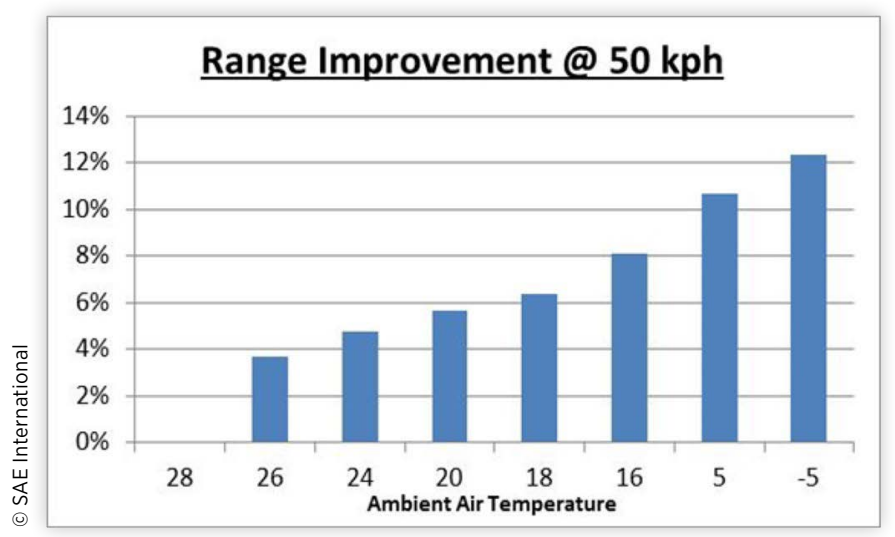

increased range. The percentage range increase, assuming the $50 \mathrm{kph}$ drive cycle, are illustrated in Figure 18.

The magnitude of the energy savings is not as high as the TS testing; however, the benefits from the waste heat gleaning has three significant attributes: no TS is required, the length of the drive cycle does not affect range improvement, and most importantly, the occurrence of dehumidification is high, which will result in significant real-world range improvement.
TABLE 1 Range extension summary for HP with the TS system (HPTS) vs. production HP vehicle for $50-\mathrm{kph}$ drive cycle

\begin{tabular}{|c|c|c|}
\hline \multirow{3}{*}{ Test Condition } & \multicolumn{2}{|c|}{ Range Extension } \\
\hline & $\mathrm{Km}$ & $\%$ \\
\hline & 6.2 & 19 \\
\hline Cold $2\left(-5^{\circ} \mathrm{C}\right)$ & 3.1 & 9 \\
\hline Cold $1\left(5^{\circ} \mathrm{C}\right)$ & 1.6 & 5 \\
\hline
\end{tabular}

TABLE 2 Range extension for PTC-only vehicle modified to include the TS system (POTS)

\begin{tabular}{|c|c|c|}
\hline \multirow[b]{2}{*}{ Test Condition } & \multicolumn{2}{|c|}{ Range Extension } \\
\hline & $\mathrm{Km}$ & $\%$ \\
\hline Cold $3\left(-18^{\circ} \mathrm{C}\right)$ & 7.5 & 22 \\
\hline Cold $2\left(-5^{\circ} \mathrm{C}\right)$ & 6.7 & 20 \\
\hline Cold $1\left(5^{\circ} \mathrm{C}\right)$ & 3.1 & 9 \\
\hline
\end{tabular}

As a follow-on activity, NREL will model the final system configuration and apply its national-level modeling process to estimate the range impact of the PTC-only with TS system. This analysis will account for yearly weather data, vehicle population distribution, time-of-day driving behavior, and real-world representative drive cycles. Results will show both national- and regional-level impacts on vehicle energy use.

\section{Range Extension}

Table 1 shows the range extension achieved with the enhanced HP vehicle for the three temperatures tested. The range extension calculations are straightforward. For each test, the total HVAC energy is calculated for the 40 -minute, $33.3-\mathrm{km}$ trip (40 minutes at $50 \mathrm{kph}=33.3 \mathrm{~km}$ ). The total battery energy use per kilometer is also computed for each trip. The HVAC energy reduction resulting from the enhancements is then divided by the total battery energy use per kilometer for the enhanced vehicle. This gives an additional distance the test car can now travel, and this incremental length divided by the base distance yields the percent range increase beyond $33.3 \mathrm{~km}$.

Table 2 shows the range extension values for the PTC-only vehicle enhanced with the TS system for the 40-minute, 50-kph drive. Again, as for all wind tunnel tests, the controls were set to "72 Auto." The range extension values are higher than those of the HP vehicle for two main reasons: 1) the baseline PTC-only vehicle uses significantly more energy for heating than the HP vehicle does, creating more room for improvement, and 2) the POTS vehicle included waste heat recovery, whereas the baseline PTC-only vehicle does not. Once modified with the TS system, both vehicles consumed similar HVAC energy, resulting in a greater improvement for the PTC-only vehicle.

\section{Baseline HP Compared to POTS}

Comparison of HVAC energy consumption between baseline $\mathrm{HP}$ and POTS is revealing. Consider, for example, an electric 
FIGURE 19 Comparison of HVAC energy consumption at $5{ }^{\circ} \mathrm{C}$ of baseline HP and POTS system

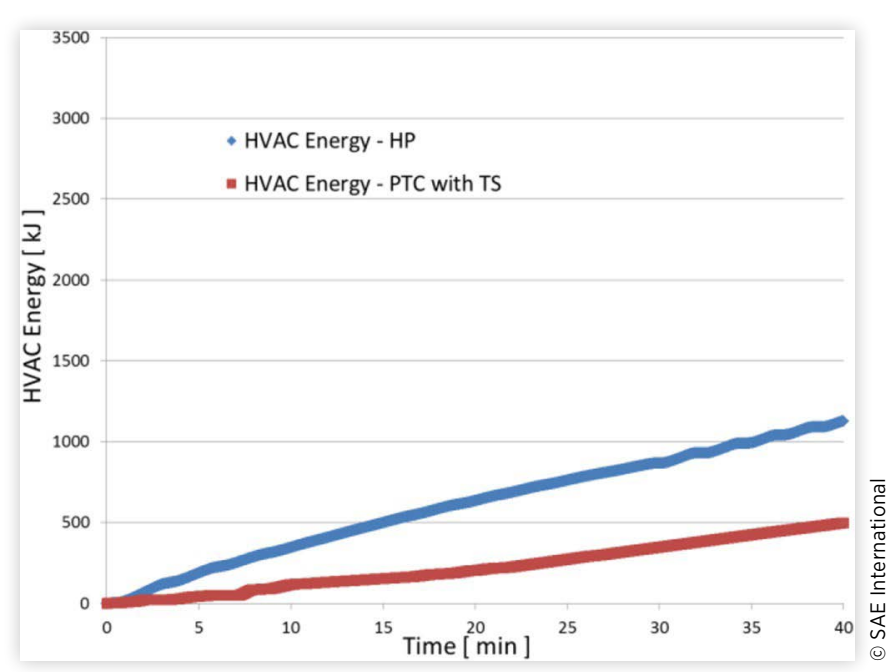

FIGURE 20 Comparison of HVAC energy consumption at $-5{ }^{\circ} \mathrm{C}$ of baseline HP and POTS System

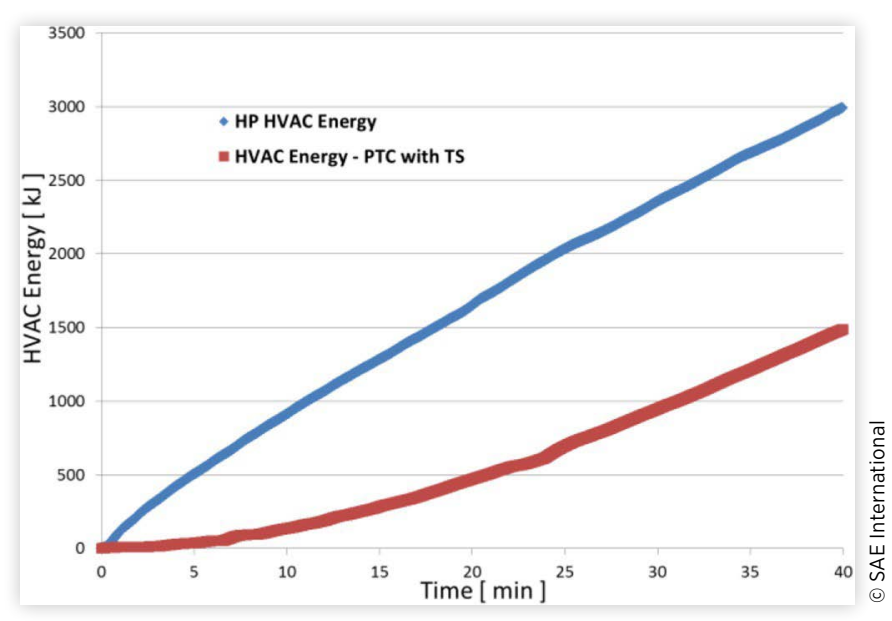

vehicle manufacturer that has the choice of adding an $\mathrm{HP}$ or a TS system. Which should they choose? Figures 19, 20, and 21 illustrate the HVAC energy consumption comparison at $5{ }^{\circ} \mathrm{C}$, $-5{ }^{\circ} \mathrm{C}$, and $-18{ }^{\circ} \mathrm{C}$ for a baseline $\mathrm{HP}$ system and a PTC-only with TS system. As the figures show, for this drive cycle with preheating, at these ambient conditions, adding TS results in significantly less HVAC energy consumption than adding an HP.

On the energy vs. time plots, it is interesting to note the slope of the red lines, for the PTC with TS, in Figures 19, 20, and 21 , which is the instantaneous power consumption of the HVAC systems. In all cases, but more obvious in Figure 20, the slope starts out very shallow, as most of the heating power is obtained from TS. As the TS is depleted, the slope increases as the HVAC power increase to compensate for the reduction of heat from TS. Near the end of the 40-minute test, the TS is nearly depleted, so the slope indicates the power requirement of the modified PTC vehicle without the assistance of TS. POTS HVAC energy consumption continues to enjoy a benefit vs. production PTC-only as waste heat from the motor is transferred to the cabin via the preCon. This feature, injecting waste
FIGURE 21 Comparison of HVAC energy consumption at $-18^{\circ} \mathrm{C}$ of baseline HP and POTS system

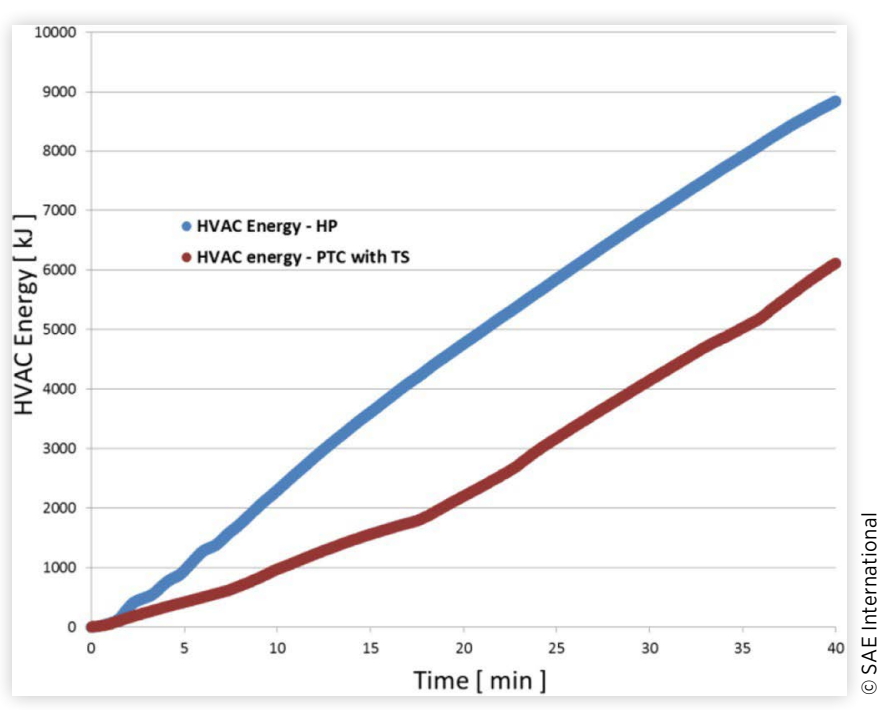

heat into the HVAC air stream, is not available on the baseline $\mathrm{HP}$ or PTC car and is referred to as direct waste heat recovery.

\section{Summary/Conclusions}

A Kia Soul BEV equipped with an optional HP was chosen for the development vehicle. In addition to developing and demonstrating the TS system concepts on the HP vehicle, the range-extending technologies were also installed and evaluated on a production Kia Soul BEV with a PTC heater as the only heat source.

The TS system consisted of three main parts: 1) the TS mass, which consisted of the traction motor and other power electronics (excluding traction battery); 2) the preCon and associated hoses and valves, which deliver stored and/or waste heat to the HVAC airstream; and 3) grill shutters and improved front-end sealing. Although additional concepts were evaluated, they returned a poor value.

This development effort successfully demonstrated a 5\% - $22 \%$ range extension for a BEV while heating without negatively impacting the interior temperature. The smaller rangeextension values are for milder conditions, as the baseline systems use less energy at these temperatures. The range extensions were similar, although larger, when the TS system was added to the PTC-only vehicle.

Figure 22 shows the HVAC energy consumption for all four vehicles (baseline HP, HPTS, baseline PTC, and POTS) at the three temperatures tested $\left(5^{\circ} \mathrm{C},-5{ }^{\circ} \mathrm{C}\right.$, and $\left.-18{ }^{\circ} \mathrm{C}\right)$. The most significant take-away is that the addition of the TS system benefits both the HP system and the PTC system tremendously. In fact, at these specific conditions, the inclusion of the TS system with preheating is so dominant that it nearly overwhelms whether the base system was HP or PTC, resulting in nearly equal energy consumption for systems equipped with the TS system.

Also, the percent energy reduction is higher for milder temperatures $\left(78 \%, 60 \%\right.$, and $49 \%$ at $5{ }^{\circ} \mathrm{C},-5^{\circ} \mathrm{C}$, and $-18{ }^{\circ} \mathrm{C}$, 
FIGURE 22 Comparison of HVAC energy consumption for all systems at all temperatures tested

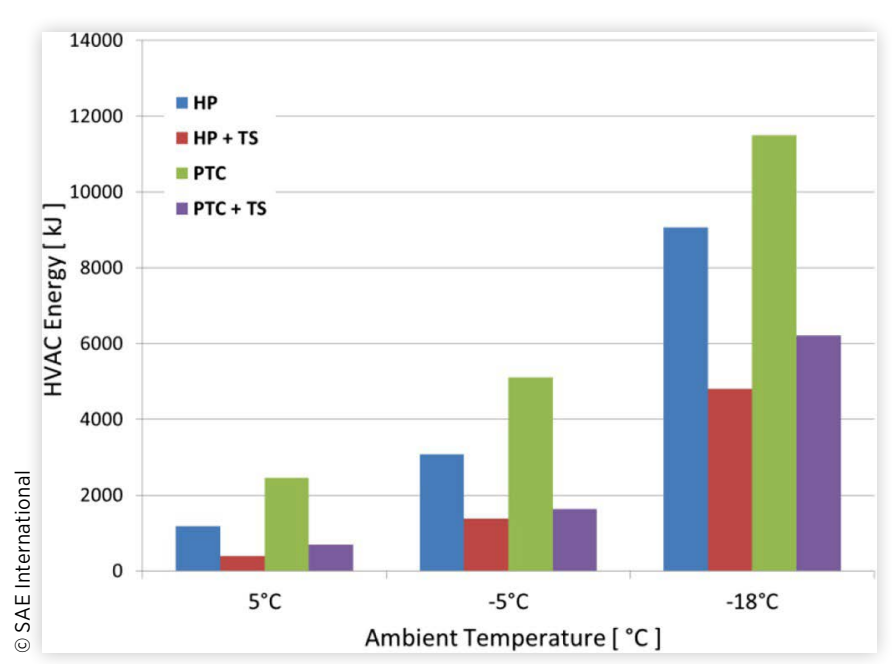

respectively), but the magnitude of the energy reduction, and thus range extension, is lower $(1.8 \mathrm{~km}, 3.4 \mathrm{~km}$, and $6.5 \mathrm{~km}$, respectively).

This simple and straight-forward TS system with preCon requires no further inventions, is effective at reducing heating loads for both HP and PTC vehicles, and is production ready.

\section{Recommendations for Future Research}

\section{Minimize Negative Effect of HP Hardware}

Testing revealed that the incremental HP hardware has an adverse effect on cooling efficiency. The HP hardware also increases the vehicle's mass, which increases the traction battery power required to move the vehicle. Rather than focus solely on the benefits of an HP system, the complete vehiclelevel impact, operating or not operating, should be evaluated and optimized.

\section{Evaluate Impact for Different Drive Cycles}

The single, steady drive cycle was chosen for this project to facilitate model validation and to reduce the number of changing variables for clarity of data reduction. Now that this drive cycle is well understood and documented, the next step is to include more realistic user cycles.

\section{Understand and Improve Refrigerant Charge Management}

Whether operating as an air conditioning (AC) or a HP system, the performance of the vapor-compression system depends on refrigerant charge level. Although this system utilizes a receiver-dryer for refrigerant charge storage during AC operation and an accumulator for HP, care must be taken to ensure proper refrigerant charge level during various modes of operation. Designing a system to operate efficiently as both an $\mathrm{AC}$ and $\mathrm{HP}$ is not a trivial task, as the AC and HP systems require significantly different charge levels during operation.

\section{Define Most Efficient Method to Achieve Target Discharge Temperature}

When embarking on a trip with heated TS, it is possible to provide $100 \%$ of the cabin heat load with warm glycol delivered to the preCon. However, as TS is depleted, there comes a time where a small amount of heat must be added to the airstream to meet the desired discharge temperature. For example, at $-5{ }^{\circ} \mathrm{C}$ the preCon may warm the air to $40{ }^{\circ} \mathrm{C}$ but the desired discharge temperature is $45^{\circ} \mathrm{C}$. What is the best way to warm the air from $40^{\circ} \mathrm{C}$ to $45^{\circ} \mathrm{C}$ ? Detailed experiments may be needed to determine energy flow for such conditions and thus define an optimum control strategy.

\section{Most Efficient Means of Waste Heat Recovery}

"Waste heat recovery" is a common phrase used to describe using waste heat to help heat the cabin. However, there are at least two ways to accomplish this. The common way is as a heat source for the HP (indirect waste heat recovery). In this arrangement, waste heat is removed from the electronics with glycol flow and delivered to the refrigerant in a chiller. The refrigerant is then compressed and heated in the compressor before flowing through the condenser, releasing heat to the cabin. There are two main drawbacks to this configuration. The first is that the only way to recover waste heat is to power the compressor. If the compressor remains off, heat is not recovered. The second is that the HVAC power consumption may be reduced by far less than the amount recovered. Consider, for example, the HP operation on a cold day where the vehicle heat load is $3 \mathrm{~kW}$. Without waste heat recovery, the outside heat exchanger may absorb, for example, $1 \mathrm{~kW}$ from the ambient air and the compressor requires $500 \mathrm{~W}$, yielding an HP capacity of $1.5 \mathrm{~kW}$. The PTC will then need to consume $1.5 \mathrm{~kW}$ to satisfy the vehicle load of $3 \mathrm{~kW}$. In this case, $3 \mathrm{~kW}$ of heat "costs" the vehicle $2 \mathrm{~kW}$ of power. If $1 \mathrm{~kW}$ of waste heat is added to the refrigerant, the heat absorbed from the ambient is drastically reduced to (for example) $500 \mathrm{~W}$. The compressor power may then increase to $750 \mathrm{~W}$, yielding $2.25 \mathrm{~kW}$ of $\mathrm{HP}$ power. The PTC power can now be reduced to $750 \mathrm{~W}$ and still meet the cabin load. The indirect waste heat recovery system provides $3 \mathrm{~kW}$ of heat at an expense of $1.5 \mathrm{~kW}$ of battery power. The addition of waste heat reduced the "free" energy absorption and thus reduced the possible benefit.

Waste heat is recovered for this project by flowing glycol containing waste heat into the HVAC case, where it gives the heat to the incoming air stream (direct waste heat recovery). This delivery method does not require compressor operation, 
and it does not affect the HP system. It simply reduces the heat load that the HVAC system must provide. A thorough evaluation of the pros and cons of direct and indirect waste heat recovery is warranted.

\section{Comparison of Adding Either an HP or a TS System to a Base PTC-Only Vehicle}

Included in this effort was an evaluation of the PTC-only (non-HP) Kia Soul BEV. It was retro-fitted with the TS system, which contains a heater for building TS, a preCon in the HVAC case, hoses and controls enabling their operation, and grill shutters with improved front-end sealing. Limited testing at a few cold temperatures and a single, steady-state drive cycle indicates that there is significant battery energy savings when adding the TS system to the base PTC-only versus adding a HP system. The HP with TS system uses the least battery energy, but when evaluating what technology to add to a base PTC system, a TS system may be a better value than a HP.

A significant benefit derived from adding the TS system is the addition of the preCon to the HVAC case. The preCon allows waste heat to be delivered directly to the cabin. A study of various drive cycles and ambient temperatures evaluating relative benefit due to TS and direct waste heat recovery may lead to an improved system. Additional work to define the pros and cons of adding a TS system or an HP system across different drive cycles and ambient temperatures is warranted. As part of the study, an examination of the relative benefits of direct waste heat recovery and TS may be revealing.

\section{References}

1. Kia website; https://www.kiamedia.com/us/en/models/soulev/2015\#soul-ev

2. Internal Hanon Systems data.

3. Meyer, J., Agathocleous, N., and Vespa, T., "Extending the Cold-Weather Range of a BEV Equipped with a Heat Pump." Thermal Management System Symposium, 2017.

4. Titov, G., Lustbader, J.A., and Daniel, L., "MATLAB/ Simulink Framework for Modeling Complex Coolant Flow Configurations of Advanced Automotive Thermal Management Systems," SAE Technical Paper 2016-01-0230, 2016, doi:10.4271/2016-01-0230.
5. Kiss, T. and Lustbader, J., "Comparison of the Accuracy and Speed of Transient Mobile A/C System Simulation Models," SAE Int. J. Passeng. Cars - Mech. Syst. 7:739-754, 2014, doi:10.4271/2014-01-0669.

\section{Contact Information}

John Meyer

jmeyer8@hanonsystems.com

\section{Acknowledgments}

The authors would like to thank David Anderson and Lee Slezak of the Department of Energy's Vehicle Technologies Office and Jason (John) Conley of the Department of Energy's National Energy Technology Laboratory for their support and guidance throughout this project. This work was supported by the U.S. Department of Energy under Contract No. DE-AC36-08GO28308 with Alliance for Sustainable Energy, LLC, the Manager and Operator of the National Renewable Energy Laboratory. Funding provided by U.S. Department of Energy Office of Energy Efficiency and Renewable Energy Vehicle Technologies Office. The U.S. Government retains and the publisher, by accepting the article for publication, acknowledges that the U.S. Government retains a nonexclusive, paid-up, irrevocable, worldwide license to publish or reproduce the published form of this work, or allow others to do so, for U.S. Government purposes.

\section{Definitions/Abbreviations}

AC - air conditioning

BEV - battery electric vehicle

HATCI - Hyundai America Technical Center, Inc.

HP - heat pump

HPTS - heat pump with thermal storage

HVAC - heating, ventilation, and air conditioning

OBC - On Board Charger

POTS - PTC-only with thermal storage

preCon - Preconditioning heat exchanger

PTC - positive temperature coefficient

TS - thermal storage

All rights reserved. No part of this publication may be reproduced, stored in a retrieval system, or transmitted, in any form or by any means, electronic, mechanical, photocopying, recording, or otherwise, without the prior written permission of the copyright holder. 